\title{
Recovery of copper and chelating agents from sludge extracting solutions
}

\author{
Fang-Chih Chang ${ }^{a}$, Shang-Lien Lo ${ }^{\mathrm{a}, *}$, Chun-Han $\mathrm{Ko}^{\mathrm{b}}$ \\ ${ }^{a}$ Research Center for Environmental Pollution Prevention and Control Technology, Graduate Institute of Environmental Engineering, \\ National Taiwan University, 71 Chou-Shan Road, Taipei 106, Taiwan, ROC \\ ${ }^{\mathrm{b}}$ School of Forestry and Resource Conservation, National Taiwan University, No. 1, Sec. 4, Roosevelt Road, Taipei 106, Taiwan, ROC
}

Received 8 December 2005; received in revised form 29 May 2006; accepted 16 June 2006

\begin{abstract}
Removal of extraction solution containing chelated copper from printed circuit board industry sludge by cementation on powdered iron was studied. This work applied the recovery and extraction of ethylene diamine tetraacetate (EDTA) and diethylene triamine pentaacetate (DTPA) as remediation agents and metal precipitated from printed circuit board sludge extracting solutions. The recovery of copper by cementation process using powdered iron was dependent on the $\mathrm{Fe}: \mathrm{Cu}$ molar ratio. Results of the experiments showed that recovery efficiencies were typical of those of a Fe:Cu molar ratio as high as 8:1 for each sludge sample. The differences of recovery efficiencies may be due to competition for active sites on the surface of the powdered iron. Copper deposits on the surface almost always occur in the form of the copper metal that are well distributed, with purified copper powder being observed in characterization with scanning electron microscopy (SEM) and X-ray powder diffraction (XRD). The recycled extract containing EDTA or DTPA was used to chelate supplementary fresh copper-containing sludge. Extraction efficiencies of copper by using Fe-precipitated EDTA or DTPA from previous cementation were higher than sequential application of the Fe-EDTA or Fe-DTPA solution. Similar copper extraction efficiencies using both pristine and reused extract containing chelants validates the enduring chelating capability of EDTA and DTPA and suggests further opportunities to employ recycled chelant to reduce its usage. This work confirmed the feasibility of copper removal from sludge chelated wastewater by cementation and subsequent recycling of chelant extraction.
\end{abstract}

(C) 2006 Elsevier B.V. All rights reserved.

Keywords: Recovery; Chelated wastewater; Copper; Chelant; Printed circuited board sludge

\section{Introduction}

Rapid industrial development and greater use of chemical products have led to a progressive increase in cases of heavy metal sludge [1]. In Taiwan, as much as $4.1 \times 10^{5}$ metric tonnes of hazardous metallic sludge are produced from electronic and computer industries annually. From environmental and economic perspectives, the retrieval of metals from waste is important. Various treatment methods have been employed, e.g., pretreatment, physical separation, thermal processes, biological decontamination, stabilization/solidification and washing [2]. Washing as well as the extraction of metals by chelants have been some of the more effective treatment methods [3-5]. The most common chelant found in the literature is ethylene diamine tetraacetic acid (EDTA) [3-11]. Studies have established that

\footnotetext{
* Corresponding author. Tel.: +88622362 5373; fax: +886223928830.

E-mail addresses: d90541003@ntu.edu.tw (F.-C. Chang), sllo@ccms.ntu.edu.tw (S.-L. Lo).
}

EDTA and DTPA can effectively remove $\mathrm{Cu}, \mathrm{Zn}, \mathrm{Pb}, \mathrm{Hg}$ and $\mathrm{Cd}$ from contaminated soil or incinerator fly ashes [3-5,7-14].

Many studies have used EDTA or DTPA for the extraction of heavy metals from contaminants. But EDTA and DTPA have the disadvantage that they are quite persistent in the environment due to their low biodegradability $[1,11,14-16]$. This may cause a rather high risk of metal leaching to the environment [16]. EDTA removes almost all natural and anthropogenic heavy metals, but its potential adverse health effects make its use difficult for treatment [17]. Additionally, to keep treatment costs low, it is necessary to achieve a cleanup so that the heavy metal can be recovered, and it should be possible to reuse the chelant for further extraction cycles. The electrochemical reduction process can remove metal ions from the synthetic solution and field samples and can deposit elemental metals on the cathodic plate to enable EDTA to be recovered for reuse from power plants $[18,19]$. But they are affected by several operating problems, e.g., membrane fouling and degradation [20]. Therefore, the cementation process is a promising technology for recovery of metal copper from copper-containing wastewater [21-26]. 


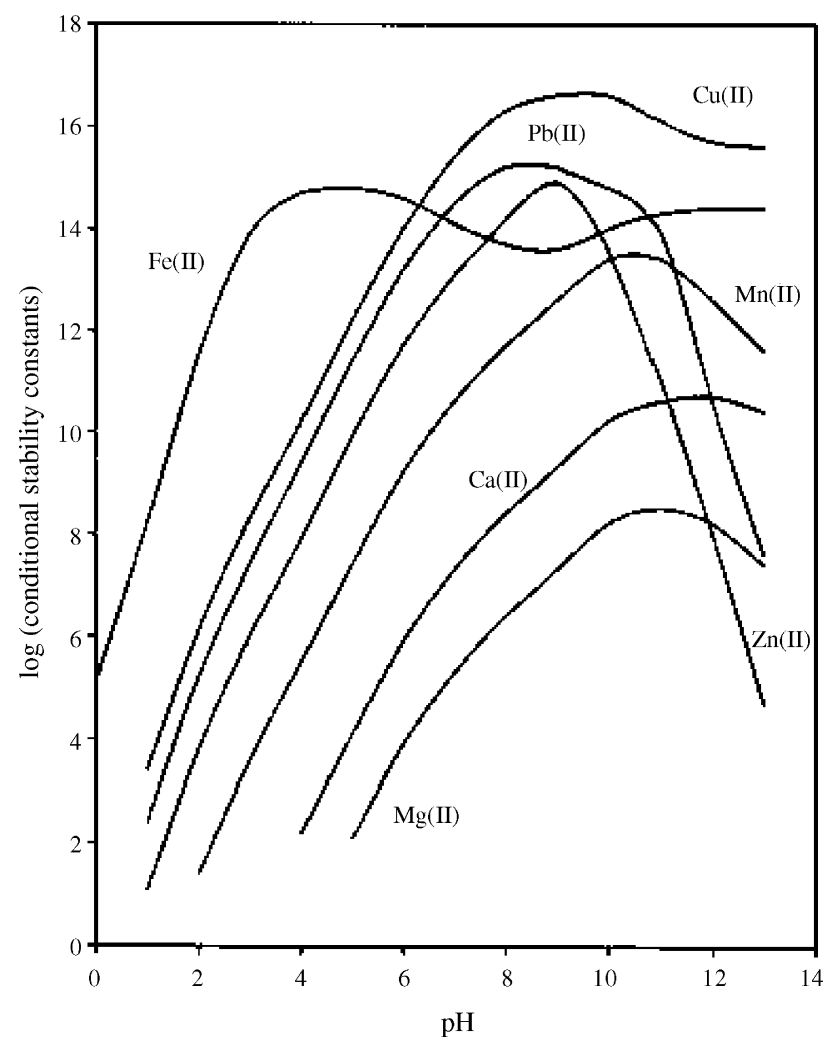

Fig. 1. Effect of $\mathrm{pH}$ on conditional stability constants of metal-EDTA complex at $20^{\circ} \mathrm{C}$ with ionic strength of $0.1 \mathrm{M}$ [20].

Cementation is used as a general term to describe the process whereby a metal is precipitated from a solution of its salts by another electropositive metal. Fig. 1 provides a comparison of conditional stability constants with $\mathrm{pH}$ for various metal-EDTA complexes. As shown in Fig. 1, it seems to be the most reasonable and simple method for recovery of copper by powdered iron (for low $\mathrm{pH}$ conditions) and results in a copper ion readily reduced on iron surface. Various studies have shown that the removal efficiency of highly concentrated heavy metal wastewater was high, regardless of heavy metal species [23-28].

EDTA and DTPA have ionic structures and dissolve better in more alkaline solutions. When acid is added to such solutions to reduce their $\mathrm{pH}$ value, dissolved EDTA and DTPA adopt a molecular structure which favors coagulation. EDTA and DTPA then precipitate by crystallization, and can be separated from heavy metals and are thus recovered. After solid/liquid separation, the supernatant can be recovered and reused again as chelants for soil extracting or flushing solutions
[14,17,20,29-30]. Most studies on this pertain to equimolar solutions of metal and chelants [20,30]. These studies differ from the case of solutions extracted from contaminated soils, as the metal concentration is very low and the solutions are characterized by a large excess of EDTA. There is a need to develop a method for recovering the high concentration chelated copper wastewater that contains strong complex formation agents such as EDTA and DTPA.

The major objective of this research was to evaluate the process of copper precipitation and the recycling of chelants from printed circuit board sludge extracting solutions. The recovery efficiency of copper was studied by cementation on powdered iron. The recovered copper has been characterized using XRD and SEM. The effectiveness of recycling chelants for repeated use in the treatment of copper-containing sludge is also evaluated.

\section{Materials and methods}

\subsection{Sludge characterization and preparation}

The sludge materials used in this study were taken from two printed circuit board factories (sludges A and B) and a metal surface treatment plant (sludge $\mathrm{C}$ ) in Taiwan. The sludges were dehydrated in an oven at $60^{\circ} \mathrm{C}$ for $48 \mathrm{~h}$, then pulverized and sieved to $<2 \mathrm{~mm}$, and stored in glass containers until analysis. All of the sludges in this study were oven-dried. Sludge properties are shown in Table 1 . The total concentrations of heavy metals in the sludges were determined using inductively coupled plasma atomic emission spectroscopy (ICP-AES; Jobin Yvon-JY24), following acid digestion [31]. The three sludges contained high $\mathrm{Cu}$ concentrations, especially sludge A. The molar sum of the heavy metals $\mathrm{Pb}, \mathrm{Cd}, \mathrm{Cr}, \mathrm{Cu}, \mathrm{Zn}$ and $\mathrm{Ni}$ was $4.55 \mathrm{mmol} \mathrm{g}^{-1}$ for sludge A, $1.94 \mathrm{mmol} \mathrm{g}^{-1}$ for sludge $\mathrm{B}$ and $1.78 \mathrm{mmol} \mathrm{g}^{-1}$ for sludge C. Mobility of metal in the samples was evaluated by using the sequential extraction scheme of BCR (the BCR method which was researched by the European scholars [32]). This scheme is a three-step sequential extraction procedure that was proposed to harmonize and validate the methods used for speciation studies in soils and sediments. It was designed based on acetic acid extraction (step 1), hydroxylamine hydrochloride extraction (step 2), and hydrogen peroxide oxidation and ammonium acetate extraction (step 3 ). These extractions are associated with the exchangeable, water and acid soluble phase (bound to carbonate, step 1), the reducible phase (bound to iron and manganese oxides, step 2), and the oxidizable phase (bound to organic matter, step 3). The results of BCR sequential extraction

Table 1

Sludge properties

\begin{tabular}{|c|c|c|c|c|c|c|c|c|c|c|c|c|c|}
\hline \multirow[t]{2}{*}{ Sludges } & \multirow[t]{2}{*}{$\mathrm{pH}$} & \multirow[t]{2}{*}{$\begin{array}{l}\mathrm{Ca} \\
(\mathrm{g} \mathrm{kg}-1)\end{array}$} & \multirow[t]{2}{*}{$\begin{array}{l}\mathrm{Fe} \\
(\mathrm{g} \mathrm{kg}-1)\end{array}$} & \multirow[t]{2}{*}{$\begin{array}{l}\mathrm{Pb} \\
(\mathrm{mg} \mathrm{kg}-1)\end{array}$} & \multirow[t]{2}{*}{$\begin{array}{l}\mathrm{Cd} \\
(\mathrm{mg} \mathrm{kg}-1)\end{array}$} & \multirow[t]{2}{*}{$\begin{array}{l}\text { Total } \mathrm{Cr} \\
(\mathrm{mg} \mathrm{kg}-1)\end{array}$} & \multirow[t]{2}{*}{$\begin{array}{l}\mathrm{Cu} \\
(\mathrm{g} \mathrm{kg}-1)\end{array}$} & \multirow[t]{2}{*}{$\begin{array}{l}\mathrm{Zn} \\
(\mathrm{g} \mathrm{kg}-1)\end{array}$} & \multirow[t]{2}{*}{$\begin{array}{l}\mathrm{Ni} \\
(\mathrm{g} \mathrm{kg}-1)\end{array}$} & \multirow[t]{2}{*}{$\begin{array}{l}\text { Sum of heavy metals } \\
(\mathrm{mol} \mathrm{kg}-1)\end{array}$} & \multicolumn{3}{|c|}{$\begin{array}{l}\text { Leaching concentration } \\
(\mathrm{mg} 1-1)\end{array}$} \\
\hline & & & & & & & & & & & $\mathrm{Cu}$ & $\mathrm{Zn}$ & $\mathrm{Ni}$ \\
\hline A & 9.15 & 84.5 & 3.2 & $<0.3^{\mathrm{a}}$ & $<0.04$ & $<0.04$ & 282.7 & 2.8 & 3.5 & 4.55 & 484.2 & 9.5 & 42.8 \\
\hline B & 6.54 & 59.8 & 160.6 & 100.0 & $<0.04$ & $<0.04$ & 120.9 & 0.8 & 1.2 & 1.94 & 2278.0 & 18.3 & 65.9 \\
\hline $\mathrm{C}$ & 8.62 & 44.3 & 22.6 & $<0.3$ & $<0.04$ & 683.0 & 94.1 & 9.2 & 8.3 & 1.78 & 611.4 & 97.6 & 61.2 \\
\hline
\end{tabular}

\footnotetext{
a Not applicable, all values below detection limits.
} 


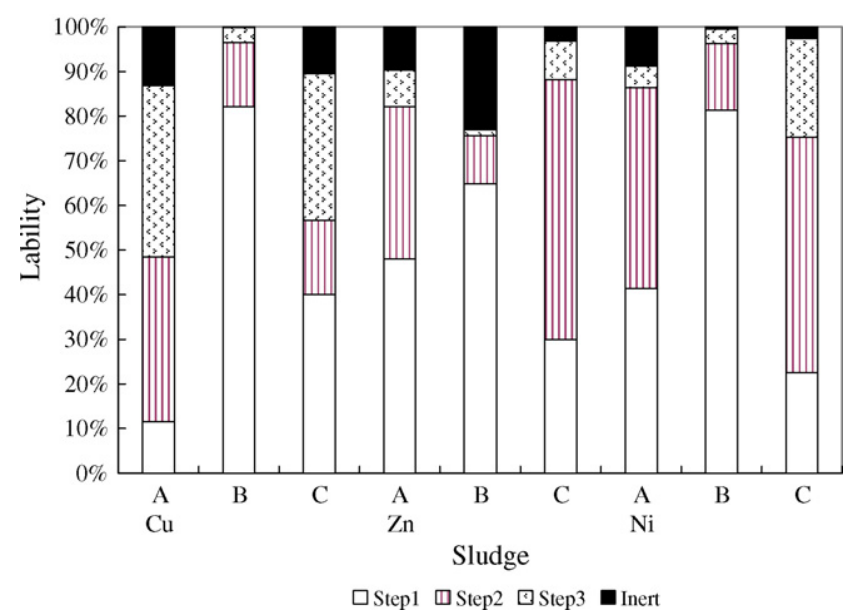

Fig. 2. Mobility of studied metals from initial sludge given as percentage of heavy metals concentration.

[32] of metals from the sludge are shown in Fig. 2. The sludge differed in the modes of metal retention within the sludge. In sludge $\mathrm{A}, \mathrm{Cu}$ was mostly accumulated in step 2 (37\% of all fractions) and step $3(38 \%)$. On the other hand, for sludge B, Cu in step 1 accounted for $82 \%$ of the total amount obtained by summation of all fractions. In sludge $\mathrm{C}, \mathrm{Cu}$ was mostly accumulated in step $1(40 \%)$ and step $3(33 \%)$.

Studies regarding the extraction of heavy metals from soil generally used a concentration of $0.005-0.1 \mathrm{M}[4,20,30,33]$. Therefore, the $0.1 \mathrm{M}$ extraction solution was used to dispose of printed circuit board wastewater sludge. The $\mathrm{pH}$ of the extraction solution is adjusted to 7 by a $1 \mathrm{M} \mathrm{NaOH}$ or $\mathrm{HNO}_{3}$ solution. Five grams of sludge were shaken with $100 \mathrm{ml} 0.1 \mathrm{M}$ EDTA or DTPA (liquid/solid ratio: 20/1) in a reciprocal shaker for $24 \mathrm{~h}$ to analyze the extraction efficiency of copper. The chelant:Cu molar ratio was 0.45 for sludge A, 1.05 for sludge B and 1.35 for sludge C. This is only $35 \%$ of the $\mathrm{Cu}$ content extracted from sludge $\mathrm{A}$, but copper that was extracted from these sludge sources by chelating agents ranged in concentration from $0.72-0.81 \mathrm{~mol} \mathrm{Cu} \mathrm{mol}^{-1}$ EDTA to $0.57-0.80 \mathrm{~mol} \mathrm{Cu} \mathrm{mol}^{-1}$ DTPA. The samples were centrifuged as before, and the supernatant was filtered through a Whatman no. 42 filter. The total concentrations of metals in the extract were determined by inductively coupled plasma atomic emission spectroscopy (ICP-AES; Jobin Yvon-JY24).

\subsection{Metal precipitation by cementation processes}

As shown in Fig. 1, ferric ions had a stronger affinity than cupric ions for EDTA, given a low $\mathrm{pH}$ (less than 5) in the sludge or solution. One molar nitric acid was added to lower the $\mathrm{pH}$ to 2.0, 3.0 and 4.0. Thereafter, powdered iron was used to break down the $\mathrm{Cu}$-EDTA or Cu-DTPA complex and copper was recovered by the following reaction [22]:

$$
\begin{aligned}
& \mathrm{Fe}(0)+\mathrm{Cu} \text {-EDTA } \rightarrow \mathrm{Fe}(\mathrm{II})-\mathrm{EDTA}+\mathrm{Cu}(\mathrm{s}) \\
& \mathrm{Fe}(0)+\mathrm{Cu}-\mathrm{DTPA} \rightarrow \mathrm{Fe}(\mathrm{II})-\mathrm{DTPA}+\mathrm{Cu}(\mathrm{s})
\end{aligned}
$$

The solutions containing chelated metals were shaken with powdered iron at Fe:Cu molar ratios of 0.5, 1.0, 1.5 , 2.0, 3.0, 4.0, 6.0,
$8.0,10.0,20.0$ and 40.0 in a reciprocal shaker with a constanttemperature water bath for $6 \mathrm{~h}$, then centrifuged, filtered and analyzed as above, to estimate the influence of the powdered iron concentration on the recovery of copper. The specific surface area of powdered iron was equal to $0.328 \mathrm{~m}^{2} / \mathrm{g}$ and the particle sizes of powder iron were $100 \mu \mathrm{m}$. A PANalytical X'Pert Pro $\mathrm{X}$-ray powder diffraction with $\mathrm{Cu} \mathrm{K} \alpha$ radiation was used to analyze the crystallinity of recovered copper. A scanning electron microscope (SEM) was used for morphological observations of the recovered copper.

\subsection{Recovery of chelant from extract}

After the recovery of copper, the reuse of extracted solution took place in three phases:

1. One molar $\mathrm{NaOH}$ was added to the solution to bring its $\mathrm{pH}$ up to 13 and permit the formation of $\mathrm{Fe}(\mathrm{OH})_{3}$ and $\mathrm{EDTA}^{4-}$ [20] or DTPA ${ }^{5-}$ :

$$
\begin{aligned}
& \text { EDTA-Fe }+\mathrm{OH}^{-} \rightarrow \mathrm{EDTA}^{4-}+\mathrm{Fe}(\mathrm{OH})_{3}(\mathrm{~s}) \\
& \text { DTPA-Fe }+\mathrm{OH}^{-} \rightarrow \mathrm{DTPA}^{5-}+\mathrm{Fe}(\mathrm{OH})_{3}(\mathrm{~s})
\end{aligned}
$$

2. The supernatant liquid was filtered through a Whatman no. 42 filter and analyzed to determine the concentration of chelant and residual copper in the solution.

3. The concentrations of chelants were indirectly measured by a total organic carbon (TOC) furnace (O-I-Analytical, model 700). The average natural organic content in the extract solution that extracts the sludge using distilled water was less than $100 \mathrm{mg} \mathrm{l}^{-1}$ and may be considered negligible.

\subsection{Extraction using recovered chelant}

The chelant solution, after precipitating its $\mathrm{Cu}$, may be used as an extraction solution again, provided the solution $\mathrm{pH}$ is adjusted to 7 by a $1 \mathrm{M} \mathrm{HNO}_{3}$ solution. The copper extraction efficiencies using the recovered EDTA or DTPA solutions with Fe-removal were compared against the results of Fe-EDTA or Fe-DTPA solutions and fresh EDTA or DTPA solutions with a similar set of extraction experiments. The concentration of Fe-EDTA or FeDTPA was adjusted to the actually measured concentration after Fe-removal. To evaluate the reproducibility of the results, all experiments were measured in triplicate samples. The diagram of metal precipitation and recovery processes are described in Fig. 3.

\section{Results and discussion}

\subsection{Sludge extraction}

Table 2 shows the results of the sludge extraction. The extracting solutions had a high copper concentration, regardless the kind of sludge or type of chelant. The concentrations of $\mathrm{Pb}, \mathrm{Cd}$, $\mathrm{Cr}, \mathrm{Zn}$ and $\mathrm{Ni}$ in solutions were relatively lower than copper. If no chelant was used, the concentration of copper in solution B was $1734.9 \mathrm{mg} \mathrm{l}^{-1}$. From BCR sequential extraction of the 


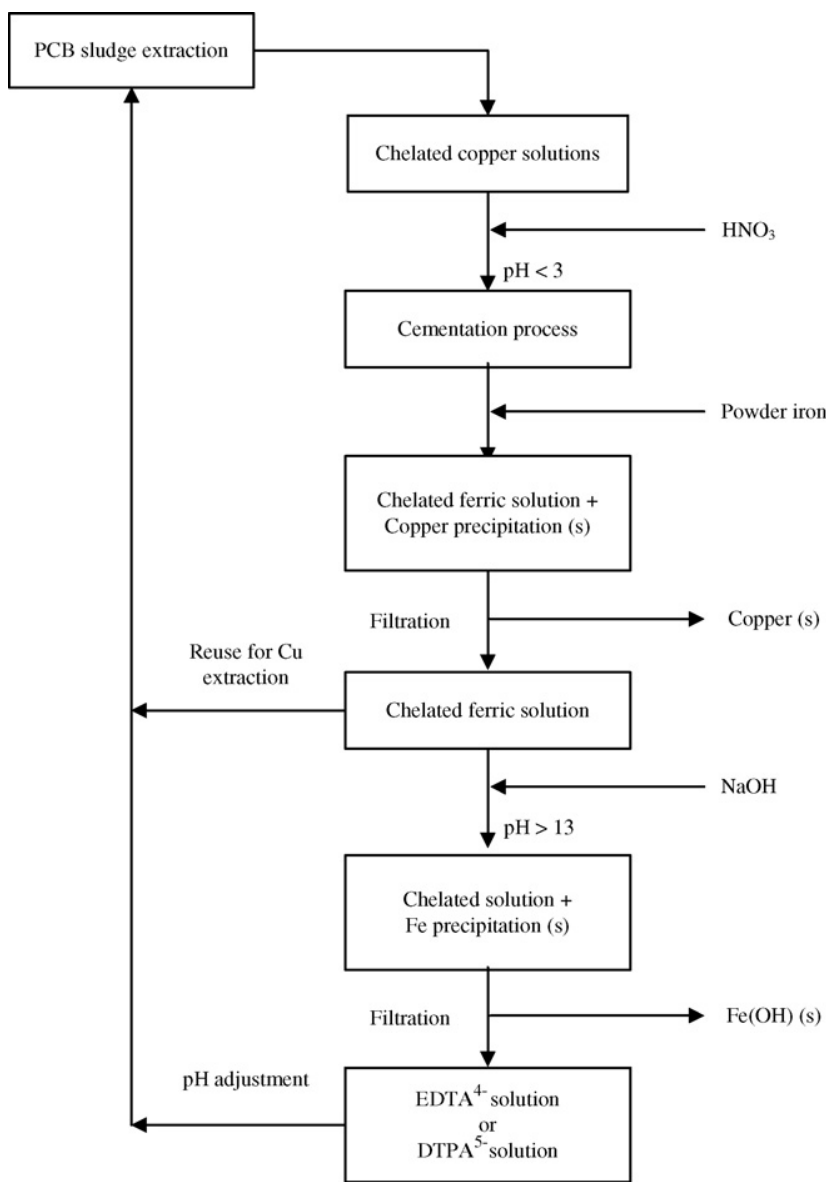

Fig. 3. Diagram of the metal precipitation and recovery process.

sludge, we found that $\mathrm{Cu}$ in step 1 for sludge $\mathrm{B}$ accounted for $82 \%$ of the total amount obtained by summation of all fractions. Therefore, the leachability of sludge B was superior to that of sludges A or C. Copper that was extracted by chelants from dry sludge ranged from $0.72-0.81 \mathrm{~mol} \mathrm{Cu} \mathrm{mol}^{-1}$ EDTA to $0.57-0.80 \mathrm{~mol} \mathrm{Cu} \mathrm{mol}^{-1} \mathrm{DTPA} / \mathrm{g}$ of sludge. DTPA was a strong effective chelant, similar to EDTA in the extraction of contaminant metals from printed circuit board sludge. Other studies performed under similar conditions have already shown that

Table 2

Percentages of heavy metals extracted from sludge at various chelants

\begin{tabular}{lllllll}
\hline Extracting solutions & $\mathrm{Pb}(\%)$ & $\mathrm{Cr}(\%)$ & $\mathrm{Cd}(\%)$ & $\mathrm{Cu}(\%)$ & $\mathrm{Zn}(\%)$ & $\mathrm{Ni}(\%)$ \\
\hline EDTA & & & & & & \\
A & $\mathrm{NA}^{\mathrm{a}}$ & $\mathrm{NA}$ & $\mathrm{NA}$ & 35.0 & 53.4 & 49.6 \\
$\mathrm{~B}$ & 89.6 & $\mathrm{NA}$ & $\mathrm{NA}$ & 85.2 & 67.5 & 96.2 \\
$\mathrm{C}$ & $\mathrm{NA}$ & 70.9 & $\mathrm{NA}$ & 97.9 & 97.4 & 98.1 \\
DTPA & & & & & & \\
A & $\mathrm{NA}$ & $\mathrm{NA}$ & $\mathrm{NA}$ & 32.7 & 58.4 & 59.3 \\
B & 95.5 & NA & NA & 83.6 & 68.5 & 99.8 \\
$\mathrm{C}$ & $\mathrm{NA}$ & 60.6 & $\mathrm{NA}$ & 93.7 & 98.3 & 98.8 \\
No chelant (pure water) & & & & & \\
A & NA & NA & NA & 0.0 & $\mathrm{NA}$ & $\mathrm{NA}$ \\
B & NA & NA & NA & 28.7 & 30.5 & 93.0 \\
C & NA & NA & NA & 0.5 & NA & 0.1 \\
\hline
\end{tabular}

${ }^{\text {a }}$ NA: not applicable, all values below detection limits.

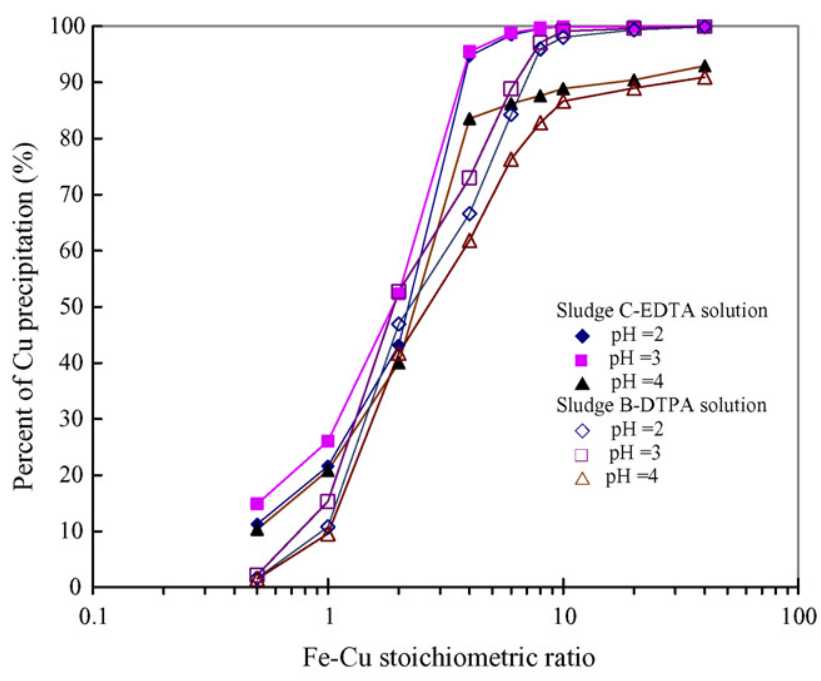

Fig. 4. Stoichiometric and $\mathrm{pH}$ effects on copper precipitation for the sludge C-EDTA solution and sludge B-DTPA solution (6-h cementation period).

the extraction of heavy metals from soil or MSW (municipal solid waste) fly ash by EDTA or DTPA was highly efficient $[5,11,14,20,30]$. However, most of these studies used artificial contaminated soils and the concentrations of heavy metals in soil or MSW fly ash were lower than that of the printed circuit board sludge used in this study. In fact, heavy metal extraction from artificially prepared sludge using chelant tended to be much easier than extraction from actual wastewater sludge, even though artificial factitious sludge may promote consistency in the sludge samples.

\subsection{Copper precipitation by cementation processes}

Copper precipitation efficiencies for different $\mathrm{Fe}-\mathrm{Cu}$ stoichiometric ratios and solution $\mathrm{pH}$ for sludge $\mathrm{C}$-EDTA and sludge B-DTPA extracting solutions are presented in Fig. 4. Cementation time for these experiments was $6 \mathrm{~h}$. The figure shows that the cementation with solution $\mathrm{pH}$ as low as 2 on a mass basis was similar to that of a solution $\mathrm{pH}$ of 3 for both extracting solutions. The cementation efficiencies were found to be dependent on the quantity of iron powder present. Considering the requirement that wastewater generated from the cementation process should be treated before disposal, reducing the mass of iron powder would reduce the treatment costs and provide additional savings with the application of chelant recovery technology. It is interesting to note that the cementation efficiency for sludge B-DTPA extracting solutions was gradual for higher $\mathrm{Fe}-\mathrm{Cu}$ stoichiometric ratios, while for sludge C-EDTA extracting solutions, the change in cementation efficiencies seemed to be quite steep for a small change in higher $\mathrm{Fe}-\mathrm{Cu}$ stoichiometric ratio. Figs. 5 and 6 show the results of copper, nickel and zinc precipitation from metal chelated wastewaters for $\mathrm{Fe}-\mathrm{Cu}$ stoichiometric ratios between 0.5 and 40 over a 6 -h cementation period with $\mathrm{pH} 2$. The figure demonstrates that copper precipitation efficiency for each extracting solution was different and that copper precipitation was a function of the stoichiometric ratio of the applied Fe concentration to the total copper concentration 


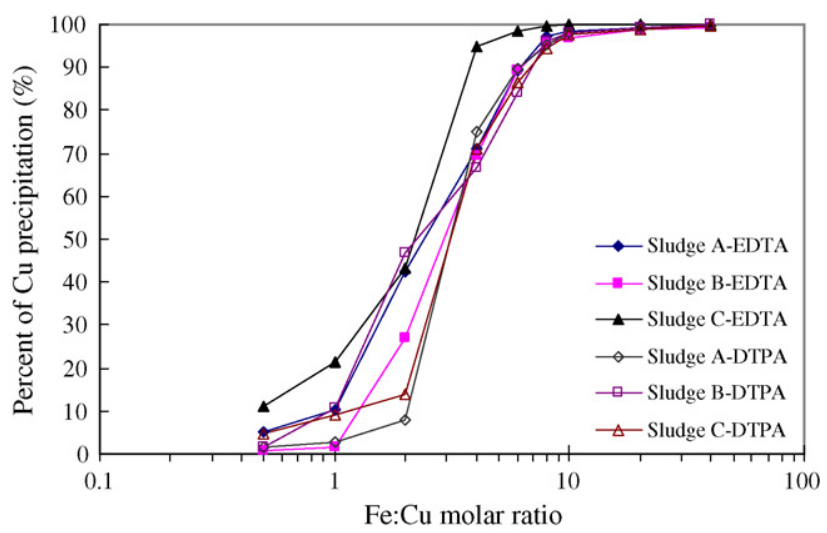

Fig. 5. Impact of iron:copper molar ratio on copper precipitation by cementation processes $(20 \mathrm{ml}$ of sludge extracting solution to iron) (6-h cementation period with $\mathrm{pH} 2$ ).

in the extracting solution. If a sufficiently large amount of $\mathrm{Fe}$ is applied, all the copper may be deposited from the extracting solution. The deposit of copper on the iron particle surface gradually coalesced as the cementation proceeded [22]. Fe undergoes oxidation more readily than Ni. However, since $E_{\text {cell }}^{0}$ is small $(+0.19 \mathrm{~V})$, it is not sensible to electroplate Fe with Ni. A cementation process using iron powder for recovering chelated zincic wastewater was impossible because $\mathrm{Zn}$ has a greater tendency to undergo oxidation than does $\mathrm{Fe}\left(E_{\text {cell }}^{0}=+0.32 \mathrm{~V}\right)$. The deposit of zinc results from the coprecipitation on copper precipitated by cementation processes [34]. The higher $\mathrm{Fe}: \mathrm{Cu}$ molar ratio was necessary as a result of the surface sites of iron already held by the deposit of copper. The iron concentrations under various experimental conditions are presented in Fig. 7. It is interesting to note that the effect of various concentrations of iron on the cementation of copper ion with $\mathrm{Fe}: \mathrm{Cu}$ molar ratios as high as

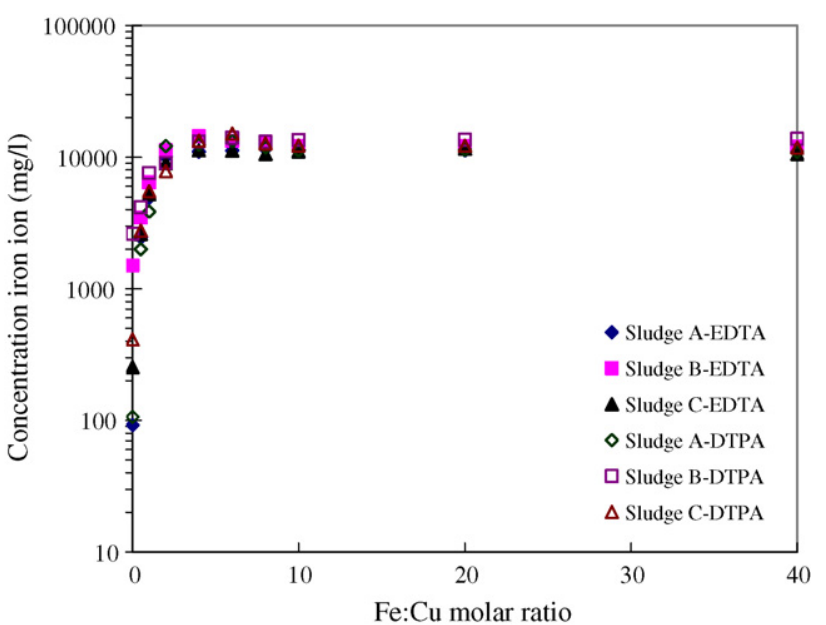

Fig. 7. Effect of iron concentrations on the cementation of copper ions in solutions of different $\mathrm{Fe}$ : $\mathrm{Cu}$ molar ratios ( $20 \mathrm{ml}$ of sludge extracting solution to iron) (6-h cementation period with $\mathrm{pH} 2$ ).

four seemed to be quite stable. The tendency of copper precipitation efficiency is similar.

Fig. 8 presents the results of XRD analysis of recovered copper from the chelated cupric wastewater with solution $\mathrm{pH}$ of 2 with $\mathrm{Fe}: \mathrm{Cu}$ molar ratios of 2 and 6 . It indicates that copper deposits on the surface almost entirely in the form of the copper molecules that are well matched with purified copper powder; no indications of any $\mathrm{Cu}-\mathrm{Fe}$ alloy or metal oxides/hydroxides were found on the surface. However, the sample is not fully crystallized. The cementation process to recover copper during the tests using various $\mathrm{Fe}: \mathrm{Cu}$ molar ratios was observed by SEM (Fig. 9). The SEM analysis shows that the cemented surface had fine, dense copper deposits of relatively uniform size with irregular iron surface possibly caused by the etching of iron.

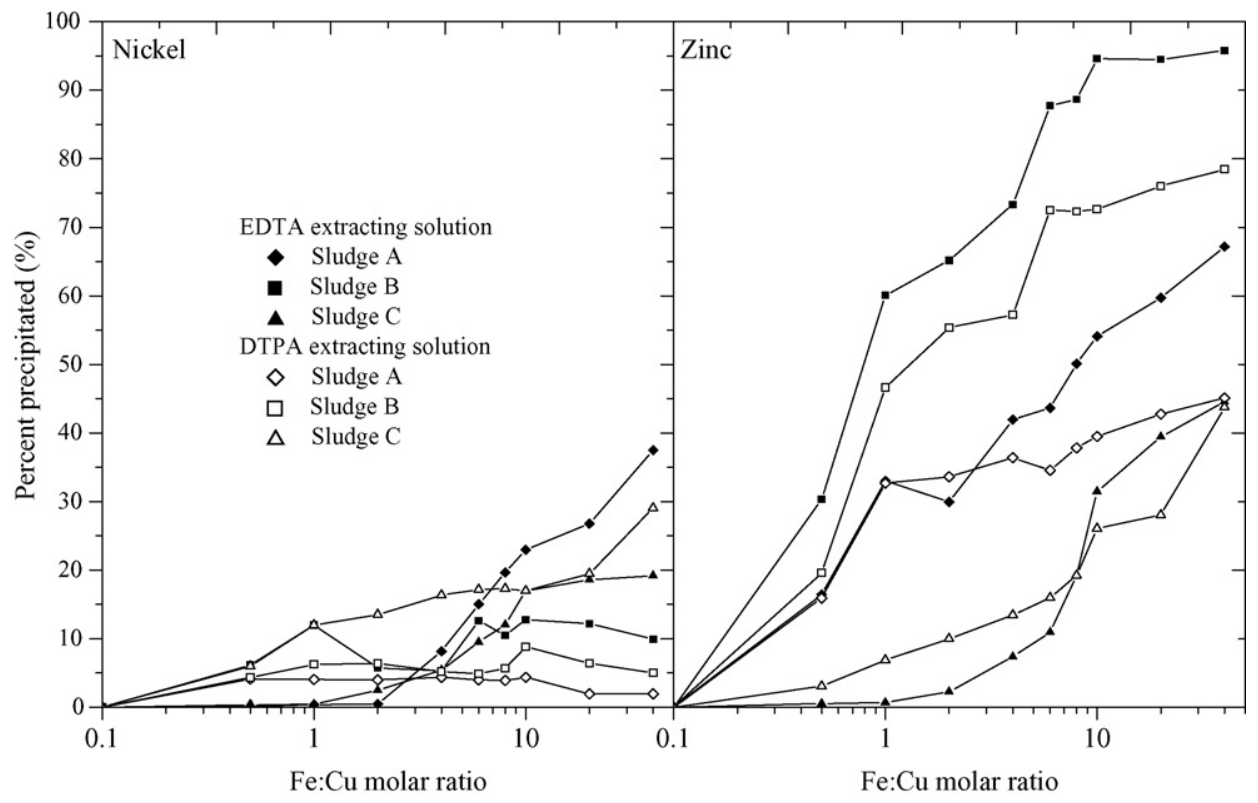

Fig. 6. Impact of iron:copper molar ratios on $\mathrm{Ni}$ and $\mathrm{Zn}$ precipitation by cementation processes ( $20 \mathrm{ml}$ of sludge extracting solution to iron) (6-h cementation period with $\mathrm{pH}$ 2). 


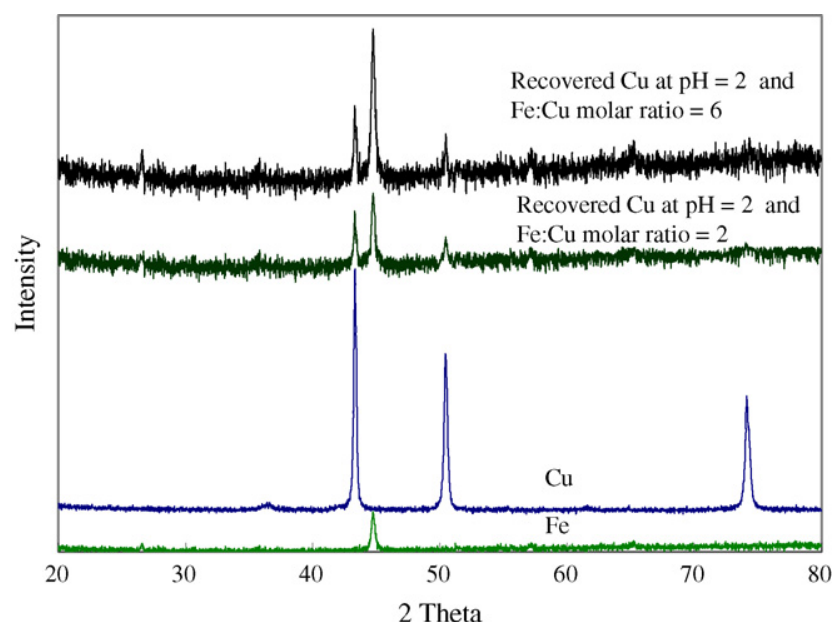

Fig. 8. X-ray powder diffraction patterns of copper prepared in different conditions for sludge A-EDTA extracting solution.

Besides this, ring-shaped copper was grown completely from the acicular copper after raising the $\mathrm{Fe}-\mathrm{Cu}$ molar ratio to 10 (see Fig. 9). It is believed that ring-shaped copper was formed during the cementation process on iron powder. The high purity of fine powder and the controllability of particle shape and size are of importance for its practical use. It is noted that the $\mathrm{Fe}: \mathrm{Cu}$ molar ratio plays an important role in determining the shape and size of the particles.

\subsection{Extraction using recovery chelant}

The recovery efficiency of chelant with Fe-precipitated chelated solution on the cementation of copper ion is shown in Fig. 10. As more powdered iron was used, a higher recovery

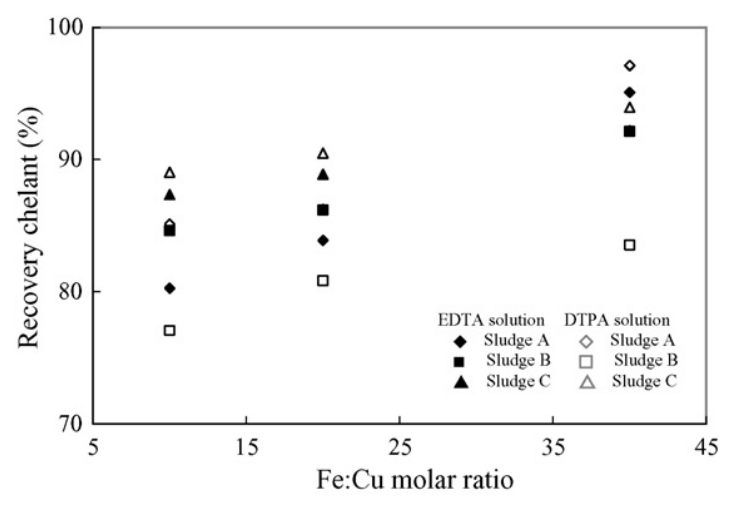

Fig. 10. Chelant recovery yield after Fe-precipitation treatment.

efficiency of EDTA and DTPA was observed. The loss of chelant should result from the adsorption of chelant within sludge in the extractive process.

Fig. 11 shows the extraction efficiencies of copper from copper-contaminated sludge (sludge A) with the chelated wastewater treated by cementation on powdered iron to precipitate copper ions, followed by $\mathrm{Fe}(\mathrm{III})$ precipitation. The reclaimed Fe-precipitated EDTA showed much higher copper extraction efficiency than in sequential applications of Fe-EDTA solution. The extraction efficiency of sequential applications of $0.1 \mathrm{M}$ EDTA dropped to approximately $45 \%$ of the extraction efficiency of fresh EDTA after the third application, while the extraction efficiency for reclaimed Fe-precipitated EDTA remained at about $57 \%$. The extraction of heavy metals was associated with the exchangeable, water and acid soluble phase (bound to carbonate, step 1) which could be easily extracted from heavy metal contaminant [32]. The models showed lower accumulation of $\mathrm{Cu}$ in step $1(11 \%)$ from the results of BCR sequential extraction of sludge $\mathrm{A}$. The molar sum of the heavy

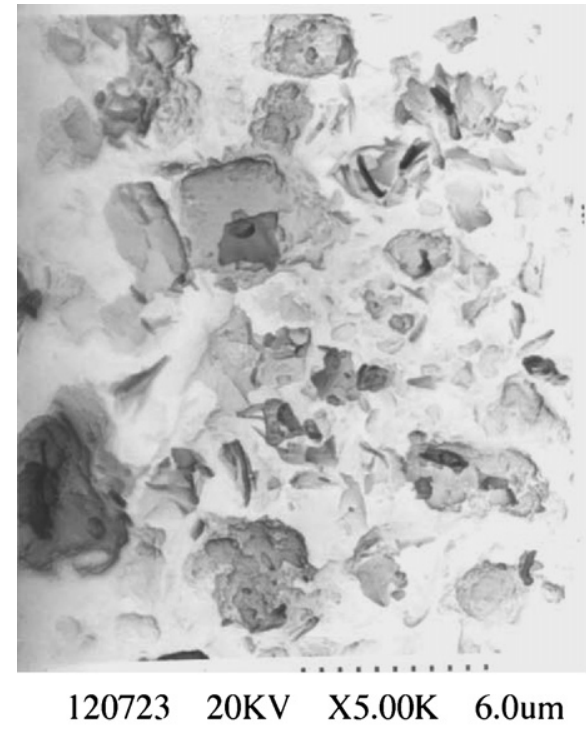

(a)

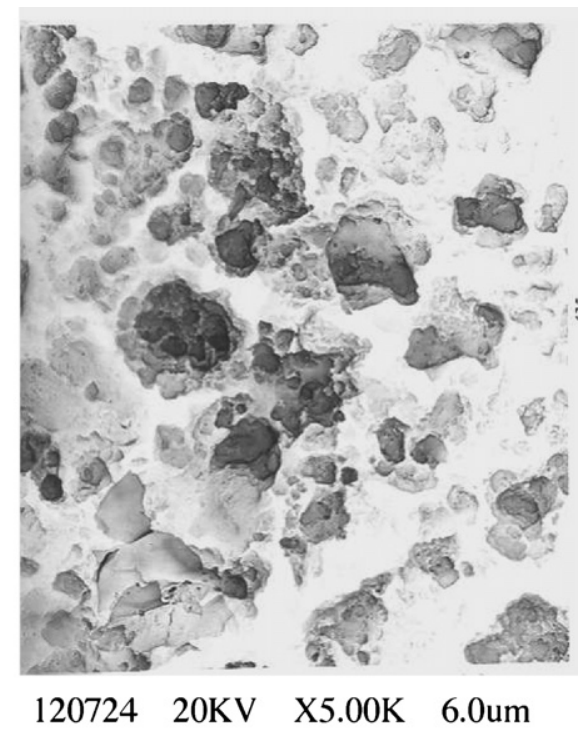

(b)

Fig. 9. Scanning electron microscopy analysis of copper prepared from sludge C-EDTA extracting solution by iron cementation ( $\mathrm{pH}$ 2) at different Fe:Cu molar ratios (a) 4:1 and (b) 10:1. 


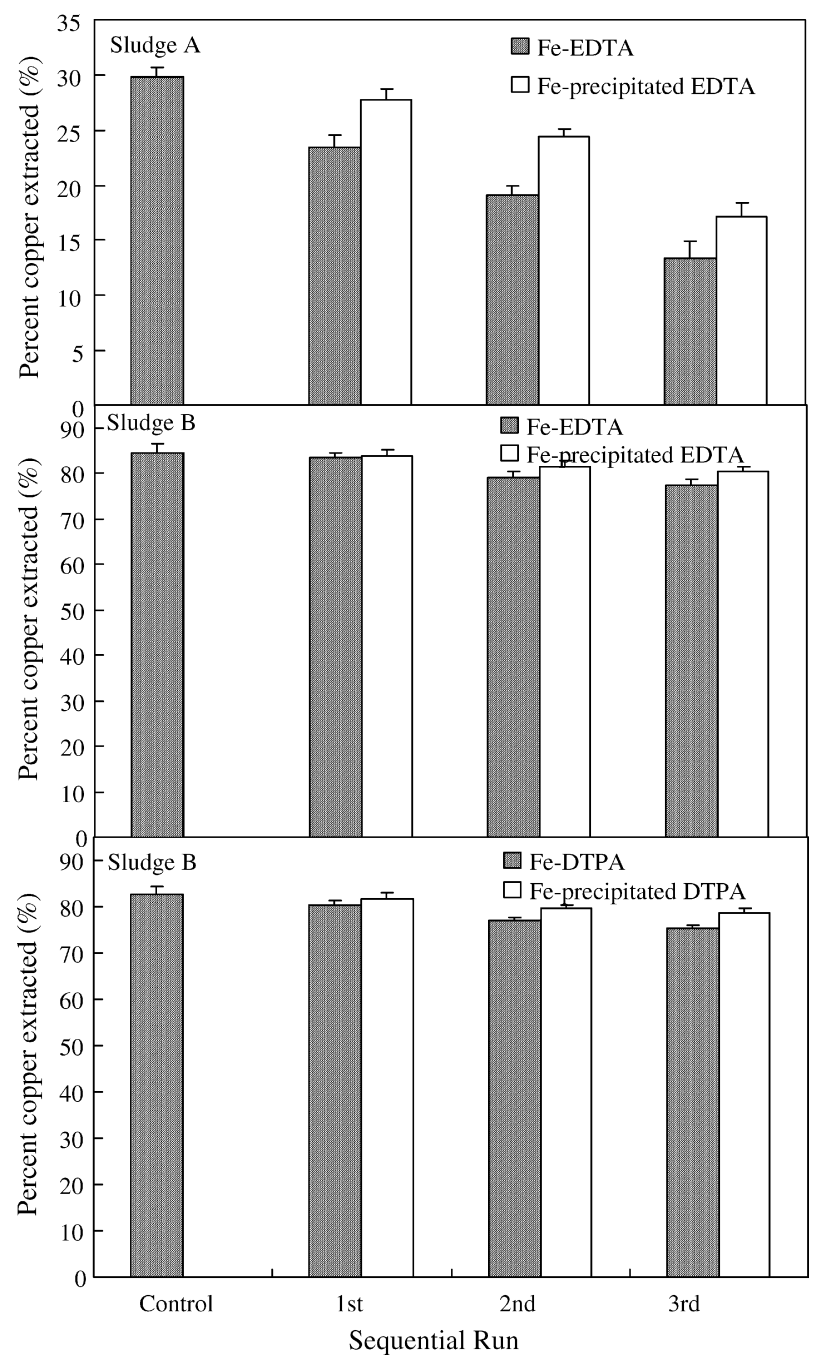

Fig. 11. Percent copper extracted from sludge with reclaimed chelated solution (S.D. for triplicates; without and with precipitated treatment at $\mathrm{pH}$ 7.0).

metals was higher in sludge A. Therefore, the copper extraction efficiency was as low as the precipitant for copper and iron.

Regarding sludge $\mathrm{B}$, the extraction efficiencies of the recycled EDTA solution were about $91 \%$ to $100 \%$ of the extraction efficiencies of fresh EDTA solution, as shown in Fig. 11. Similar results were obtained using DTPA as the extracting solution (Fig. 11), although the extraction efficiencies were slightly lower than those using EDTA. The models showed high accumulation of $\mathrm{Cu}$ in step $1(82 \%)$ from the results of BCR sequential extraction of sludge $\mathrm{B}$. Therefore, the copper extraction efficiency was as high as $82 \%$ even after being reclaimed over three cycles. The reclaimed chelated solution may be as efficient as fresh chelant for extracting copper from printed circuit board sludge, even after the chelated solution has been reclaimed for a third time.

\section{Conclusions}

The experiments using chelated wastewater performed in this study examined copper removal, recycling of chelant, and extraction of hazardous heavy metals from sludge. The results of these experiments have led us to conclude the following:
1. The extracting solutions have a high copper concentration, regardless of the kind of sludge or chelants used.

2. Cementation on powdered iron was adopted to remove or recycle the heavy metals from wastewater that contained chelated metals. Powdered iron promoted the separation of copper from copper-containing wastewater.

3. Copper deposits on the surface of the iron occurred almost entirely in the form of copper molecules that are well matched with purified copper powder.

4. The recycling of Fe-precipitated EDTA or DTPA showed much higher copper extraction efficiency than the use of sequential applications of the Fe-EDTA or Fe-DTPA solutions.

5. The copper extraction efficiency for sludge A with recycled Fe-precipitated EDTA remained about $57 \%$. However, the copper extraction efficiency for sludge B was as high as $82 \%$, even after being reclaimed over three cycles. The models of metal retention within the sludge serve to determine the extraction efficiency of metal.

6. The processes using chelated copper from hazardous metallic sludge, successive powdered iron recovery of copper from extract, and resulting reuse of chelants, are proved according to this study and interrelated literatures [20,29]. As a result of the recovery of copper and the reuse of chelants, those processes used in this study will be economically feasible to treat hazardous metallic sludge.

\section{Acknowledgements}

The authors would like to thank the Department of Industrial Technology of Ministry of Economic Affairs, ROC for financially supporting this research under Contract No. 92-EC17-A-10-S1-0007.

\section{References}

[1] C.K. Schmidt, M. Fleig, F. Sacher, H.J. Brauch, Occurrence of aminopolycarboxylates in the aquatic environment of Germany, Environ. Pollut. 131 (2004) 107-124.

[2] C.N. Mulligan, R.N. Yong, B.F. Gibbs, An evaluation of technologies for the heavy metal remediation of dredged sediments, J. Hazard. Mater. 85 (2001) 145-163.

[3] C.N. Neale, R.M. Bricka, A.C. Chao, Evaluating acids and chelating agents for removing heavy metals from contaminated soils, Environ. Prog. 16 (1997) 274-280.

[4] R.W. Peters, Chelant extraction of heavy metals from contaminated soils, J. Hazard. Mater. 66 (1999) 151-210.

[5] K.J. Hong, S. Tokunaga, T. Kajiuchi, Extraction of heavy metals from MSW incinerator fly ashes by chelating agents, J. Hazard. Mater. 75 (2000) 57-73.

[6] Z. Li, L.M. Shuman, Redistribution of forms of zinc, cadmium and nickel in soils treated with EDTA, Sci. Total Environ. 191 (1996) 95-107.

[7] B.E. Reed, P.C. Carriere, R. Moore, Flushing of a Pb(II) contaminated soil using $\mathrm{HCl}$, EDTA and $\mathrm{CaCl}_{2}$, J. Environ. Eng. ASCE 122 (1996) 48-50.

[8] R.J. Abumaizar, E.H. Smith, Heavy metal contaminants removal by soil washing, J. Hazard. Mater. 70 (1999) 71-86.

[9] B. Sun, F.J. Zhao, E. Lombi, S.P. McGrath, Leaching of heavy metals from contaminated soils using EDTA, Environ. Pollut. 113 (2001) 111-120.

[10] T. Xie, W.D. Marshall, Approaches to soil remediation by complexometric extraction of metal contaminants with regeneration of reagents, J. Environ. Monitor. 3 (2001) 411-416. 
[11] S. Tandy, K. Bossart, R. Mueller, J. Ritschel, L. Hauser, R. Schulin, B. Nowack, Extraction of heavy metals from soils using biodegradable chelating agents, Environ. Sci. Technol. 38 (2004) 937-944.

[12] J. Pichtel, T.M. Pichtel, Comparison of solvents for ex situ removal of chromium and lead from contaminated soil, Environ. Eng. Sci. 14 (1997) 97-104.

[13] A. Barona, I. Aranguiz, A. Elías, Metal associations in soils before and after EDTA extractive decontamination: implications for the effectiveness of further clean-up procedures, Environ. Pollut. 113 (2001) 79-85.

[14] P.K.A. Hong, C. Li, S.K. Banerji, Y. Wang, Feasibility of metal recovery from soil using DTPA and its biostability, J. Hazard. Mater. B 94 (2002) 253-272.

[15] M. Bucheli-Witschel, Environmental fate and microbial degradation of aminopolycarboxylic acids, FEMS Microbiol. Rev. 25 (2001) 69-106.

[16] B. Nowack, Environmental chemistry of aminopolycarboxylate chelating agents, Environ. Sci. Technol. 36 (2002) 4009-4016.

[17] R.S. Tejowulan, W.H. Hendershot, Removal of trace metals from contaminated soils using EDTA incorporating resin trapping techniques, Environ. Pollut. 103 (1998) 135-142.

[18] C.G. Rampley, K.L. Ogden, Preliminary studies for removal of lead from surrogate and real soils using a water soluble chelator: adsorption and batch extraction, Environ. Sci. Technol. 32 (1998) 987-993.

[19] C.P. Huang, M.C. Hsu, P. Miller, Recovery of EDTA from power plant boiler chemical cleaning wastewater, J. Environ. Eng. ASCE 126 (2000) 919-924.

[20] C. Kim, S.K. Ong, Recycling of lead-contaminated EDTA wastewater, J. Hazard. Mater. 69 (1999) 273-286.

[21] T. Agelidis, K. Fytianos, G. Vasilikiotis, D. Jannakoudakis, Lead removal from wastewater by cementation utilising a fixed bed of iron spheres, Environ. Pollut. 50 (1988) 243-251.

[22] Y. Ku, C.H. Chen, Removal of chelated copper from wastewaters by iron cementation, Ind. Eng. Chem. Res. 31 (1992) 1111-1115.
[23] S.S. Djokic, Cementation of copper on aluminum in alkaline solutions, J. Electrochem. Soc. 143 (1996) 1300-1305.

[24] H.H. Nguyen, T. Tran, P.L.M. Wong, A kinetic study of the cementation of gold from cyanide solutions onto copper, Hydrometallurgy 46 (1997) 55-69.

[25] T. Stefanowicz, M. Osinska, S. Napieralska-zagozda, Copper recovery by cementation method, Hydrometallurgy 47 (1997) 69-90.

[26] B. Donmez, F. Sevim, H. Sarac, A kinetic study of the cementation of copper from sulphate solutions onto a rotating aluminum disc, Hydrometallurgy 53 (1999) 145-154

[27] L. Makhloufi, B. Saidani, H. Hammache, Removal of lead ions from acidic aqueous solutions by cementation on iron, Water Res. 34 (2000) 2517-2524.

[28] B. Panda, S.C. Das, Electrowinning of copper from sulfate electrolyte in presence of sulfurous acid, Hydrometallurgy 59 (2001) 55-67.

[29] L. Di Palma, F. Medici, Recovery of copper from contaminated soil by flushing, Waste Manage. 22 (2002) 883-886.

[30] L. Di Palma, P. Ferrantelli, C. Merli, F. Biancifiori, Recovery of EDTA and metal precipitation from soil flushing solutions, J. Hazard. Mater. B 103 (2003) 153-168.

[31] U.S. EPA, Acid Digestion of Sediments, Sludges and Soils, Test Methods for Evaluating Solid Waste (SW-846-Method 3050B), U.S. Environmental Protection Agency, Washington, DC, 1996.

[32] J. Lacal, M.P. da Silva, R. García, M.T. Sevilla, J.R. Procopio, L. Hernández, Study of fractionation and potential mobility of metal in sludge from pyrite mining and affected river sediments: changes in mobility over time and use of artificial ageing as a tool in environmental impact assessment, Environ Pollut. 124 (2003) 291-305.

[33] M.A.M. Kedziorek, A.C.M. Bourg, Solubilization of lead and cadmium during the percolation of EDTA through a soil polluted by smelting activities, J. Contam. Hydrol. 40 (2000) 381-392.

[34] D.A. Skoog, D.M. West, F.J. Holler, S.R. Crouch, Analytical Chemistry: An Introduction, 7th ed., Thomson Learning, London, 1999, pp. 186-189. 